\title{
Haemodialysis and transplantation in Wegener's granulomatosis
}

\author{
CHARLES VAN YPERSELE DE STRIHOU, YVES PIRSON, JEAN-MARIE VANDENBROUCKE, \\ GUY P J ALEXANDRE
}

British Medical fournal, 1979, 2, 93-94

\section{Summary and conclusions}

Two men with Wegener's disease began immunosuppressive treatment during severe renal insufficiency. Despite an initial temporary remission new lesions appeared and renal failure progressed. Haemodialysis was started, cytotoxic drugs were stopped, and steroid dosage was reduced. All extrarenal manifestations of the disease remitted, however, suggesting a favourable effect of either the immunosuppression induced by terminal renal failure or the haemodialysis itself. Renal transplantation was then undertaken in both patients. Thirteen and 55 months after the operations respectively renal function was satisfactory and no signs of reactivation of Wegener's disease had appeared.

These results show that whatever the activity of Wegener's disease and its initial response to immunosuppressive agents, dialysis and transplantation are fully warranted once irreversible renal failure is established.

\section{Introduction}

The prognosis of Wegener's granulomatosis may be greatly improved with cytotoxic drugs, ${ }^{1}$ especially cyclophosphamide. ${ }^{2}$ Even when renal failure is irreversible the activity of the disease can be controlled, permitting dialysis and transplantation without reactivating the disease. ${ }^{3-5}$ Nevertheless, the appropriate management of patients with end-stage renal failure due to Wegener's granulomatosis whose disease remains active despite immunosuppressive treatment is not clear.

We describe two patients in whom despite treatment Wegener's disease remained active up to the point of terminal uraemia. After instituting haemodialysis the disease remitted and transplantation was successfully performed.

\section{Case 1}

A 34-year-old man developed characteristic Wegener's granulomatosis in 1971, with rhinopharyngitis, bilateral otitis media, excavated nodular lung tumours, pleuropericarditis, and severe oliguria due to a biopsy-proved necrotising focal glomerulonephritis. Haemodialysis and cytotoxic treatment (azathioprine $75 \mathrm{mg}$ daily) were instituted. One month later renal function was improved (serum creatinine concentration stable at about $221 \mu \mathrm{mol} / 1 ; 2.5 \mathrm{mg} / 100 \mathrm{ml}$ ) and extrarenal manifestations, including the lung lesions, had disappeared. Haemodialysis was stopped. Azathioprine was continued

University of Louvain Medical School, Renal and Transplantation Unit, Cliniques Universitaires St-Luc, 1200 Brussels, Belgium

CHARLES VAN YPERSELE DE STRIHOU, MD, professor of medicine YVES PIRSON, MD, physician in renal medicine

JEAN-MARIE VANDENBROUCKE, $M D$, physician in renal medicine GUY P J ALEXANDRE, MD, professor of surgery at $75 \mathrm{mg} /$ day, any larger dosage resulting in leucopenia. Twelve months later his general condition deteriorated, renal function decreased (serum creatinine $592 \mu \mathrm{mol} / 1 ; 6.7 \mathrm{mg} / 100 \mathrm{ml}$ ), and a large nasal septal necrotic ulcer appeared. Azathioprine was replaced by cyclophosphamide $100 \mathrm{mg} /$ day and prednisone $60 \mathrm{mg} /$ day at tapering dosage. Despite evident healing of the nasal lesion renal failure progressed, and four months later haemodialysis was reinstituted. At the start of haemodialysis severe leucopenia necessitated withdrawal of cyclophosphamide, and prednisone was reduced to $10 \mathrm{mg} /$ day. Although the patient received no cytotoxic drugs during the 13 months of dialysis no extrarenal manifestation of Wegener's disease reappeared. In June 1974, 35 months after onset of the disease, the patient was transplanted with a cadaver graft. An acute rejection episode eight days after operation was easily reversed with increased steroid dosage, antilymphocyte globulin, and local irradiation of the graft. Maintenance treatment included azathioprine $150 \mathrm{mg} /$ day and prednisone $10 \mathrm{mg} /$ day. Fifty-five months after transplantation renal function remained stable (serum creatinine $133 \mu \mathrm{mol} / 1 ; 1.5 \mathrm{mg} / 100 \mathrm{ml}$ ) without urine abnormalities, no signs of reactivation of Wegener's granulomatosis had been noted, and the patient was fully rehabilitated.

\section{Case 2}

A 43-year-old man developed Wegener's granulomatosis in 1976, with paranasal sinusitis, bilateral excavated lung masses, arthralgia, and renal failure (serum creatinine concentration $1503 \mu \mathrm{mol} / \mathrm{l} ; 17$ $\mathrm{mg} / 100 \mathrm{ml}$ ) due to biopsy-proved focal glomerulonephritis. Treatment with prednisone resulted in greatly improved renal function (serum creatinine $354 \mu \mathrm{mol} / 1 ; 4 \mathrm{mg} / 100 \mathrm{ml}$ ) and total disappearance of the extrarenal manifestations of the disease. Eight months later renal function deteriorated. Azathioprine $150 \mathrm{mg} /$ day was added to the prednisone $(75 \mathrm{mg} /$ day), resulting in stabilisation of renal function at a serum creatinine concentration of $796 \mu \mathrm{mol} / 1(9 \mathrm{mg} / 100 \mathrm{ml})$. Uveitis and a mononeuritis, however, developed four and six months after the institution of cytotoxic treatment. In August 1977 a further, irreversible deterioration of renal function necessitated haemodialysis. Azathioprine was stopped because of leucopenia but prednisone was continued, initially at $30 \mathrm{mg} /$ day and then in decreasing dosage. During the four months of dialysis all extrarenal manifestations of Wegener's granulomatosis disappeared. In December 1977, 23 months after onset of the disease, the patient was transplanted with a cadaver graft. Two rejection crises, 12 days and eight months after operation, were successfully reversed with increased steroid dosage, antithymocyte globulin, and local irradiation. Renal biopsy during the second rejection disclosed signs of acute rejection and moderate interstitial fibrosis compatible with mild chronic rejection; no glomerular lesions were seen. Maintenance treatment included $100 \mathrm{mg}$ azathioprine and $20 \mathrm{mg}$ prednisone daily. Thirteen months after transplantation renal function was stable (serum creatinine 150 $\mu \mathrm{mol} / 1 ; 1.7 \mathrm{mg} / 100 \mathrm{ml}$ ) without urine abnormalities, no signs of reactivation of the original disease had been noted, and the patient was fully rehabilitated.

\section{Discussion}

These two patients had unequivocal Wegener's granulomatosis. After a temporary remission obtained with azathioprine and steroids extrarenal signs of reactivation appeared-namely, nasal ulcer in case 1 and uveitis and mononeuritis in case 2. Simultaneously renal failure progressed, requiring haemodialysis to maintain life. At that stage we considered the patients for dialysis and transplantation: although successful dialysis and transplantation had been reported in four patients with 
inactive Wegener's disease, ${ }^{3-5}$ no data were available on outcome in patients apparently resistant to steroid and cytotoxic treatment when beginning dialysis. Our results, however-namely, complete remission of Wegener's disease in both cases-clearly show the value of dialysis and transplantation in such patients.

Was immunosuppression adequate when reactivation became evident ? Both patients were treated with azathioprine, though most reported cures have been achieved with cyclophosphamide. Despite the claim by Fauci et al, ${ }^{6}$ that cyclophosphamide produced complete remission in patients apparently resistant to azathioprine, no comparative series has established the superiority of cyclophosphamide over azathioprine. The low dosage of azathioprine used in our case 1 was the maximum that could be tolerated without causing leucopenia.

It is interesting to speculate why sustained remission of the extrarenal manifestations of the disease occurred during dialysis despite the apparent failure of cytotoxic treatment. This improvement was particularly striking, since institution of dialysis coincided with withdrawal of cytotoxic drugs and a large reduction in steroid dosage. It could be argued that healing was a delayed effect of cyclophosphamide in case 1 and azathioprine in case 2. This possibility is difficult to support in case 2, however, as it would imply a delay in action of at least six months after instituting the drug. Alternatively, remission might have been induced by immunosuppression associated with terminal renal failure. ${ }^{7}$ Finally, haemodialysis itself should be considered. Haemodialysis may remove immune complexes from the circulation, ${ }^{8}$ and this mechanism was suggested to account for dialysis-associated remission in lupus disease. ${ }^{9}$ If active Wegener's disease is also associated with circulating immune complexes ${ }^{610}$ a similar mechanism might operate, but we have no data to confirm or refute this. Measuring immune complexes before and after instituting haemodialysis might provide an answer.

Our findings together with other reports ${ }^{3-5}$ show that whatever the activity of Wegener's disease and its response to cytotoxic agents dialysis and transplantation are fully warranted once irreversible renal failure is established. There were no signs of reactivation of the disease 13 and 55 months after transplantation in our two patients and 10 and 28 months after transplantation in two cases reported elsewhere. ${ }^{5}$

We thank Drs $\mathrm{H}$ J Steyaert and $\mathrm{H}$ W Baisier for referring the patients. This paper was presented in part at the Société de Néphrologie, Paris, in February 1979.

Requests for reprints should be addressed to: Professor C van Ypersele, Service de Néphrologie, Cliniques Universitaires St-Luc, 1200 Bruxelles, Belgium.

\section{References}

${ }^{1}$ Lancet, 1972, 2, 519.

${ }^{2}$ Fauci, A S, and Wolf, S M, Medicine, 1973, 52, 535.

${ }^{3}$ Lyons, G W, and Lindsay, W G, American fournal of Surgery, 1972, 124, 104.

${ }^{4}$ Kjellstrand, C M, et al, Archives of Internal Medicine, 1974, 134, 40.

${ }^{5}$ Fauci, A S, et al, American fournal of Medicine, 1976, 60, 437.

${ }^{6}$ Fauci, A S, Haynes, B F, and Katz, P, Annals of Internal Medicine, 1978 89,660 .

7 Wilson, W E C, Kirkpatrick, C H, and Talmage, D W, Annals of Internal Medicine, 1965, 62, 1

${ }^{8}$ Ahlin, T D, et al, American fournal of Medicine, 1978, 64, 672

${ }^{9}$ Coplon, N, Siegel, R, and Fries, J, Transactions: American Society for Artificial Internal Organs, 1973, 19, 302.

10 Howell, S B, and Epstein, W V, American Fournal of Medicine, 1976, 60, 259.

(Accepted 1 fune 1979)
ONE HUNDRED YEARS AGO The new building of the British Hospital in the Rue de Villiers, Paris, was formally opened for the reception of patients on the 16th instant by Lord Lyons. His Excellency was received at the principal entrance by Sir Richard Wallace, founder of the hospital; Lady Wallace; Sir John Rose Cormack, and the Honourable Alan Herbert (the two physicians); Miss Smith, lady-superintendent; and other members of the staff, who, together with a number of ladies and gentlemen, present by invitation of Sir Richard, accompanied Lord Lyons in visiting the different parts of the institution. The proceedings commenced by Sir Richard Wallace reading to Lord Lyons the following account of the origin, objects, and working of the institution.

"On the 24th August, 1877, the seventh anniversary of the death of the late Marquis of Hertford, the foundation stone of this building was laid by Lady Wallace and me. At that date, the Hertford British Hospital had already existed for about six years. It grew up, so to speak, during the two sieges of Paris. In its origin, it was an appendix to my 'Ambulance Anglaise,' which had its headquarters in the Rue d'Aguesseau. Early in January 1871, during the most distressing period of the German siege, the want of hospital accommodation for poor British subjects was so urgent, that I opened wards for their reception immediately adjoining those which were occupied in the Rue d'Aguesseau by the sick and wounded soldiery. There, also, from 1st January to 31 st July, 1871, non-resident patients received gratuitously advice and medicines. On the 1st August, 1871, the civil patients, and our remaining wounded soldiers, were transferred to a commodious house fitted up for their reception at Levallois-Perret, whence, on 15th November, 1871, removal took place to the premises in the Route de la Révolte, which we have just quitted to come to the new building.

"My idea in founding the Hertford British Hospital has been to raise a suitable monument in memory of the generosity and noble qualities of the late Lord Hertford; and at the same time to give the British sick poor of Paris a comfortable home to which they can come to have their maladies cured or alleviated under the care of experienced physicians, a lady-superintendent, and nurses of their own country; and in which provision is made for the consolation of religion-each patient, however, having the free exercise of his own faith and access to his own minister. The ordinary patients are British subjects; but all persons overtaken by accident in this neighbourhood, and in urgent need of surgical aid, are at once admitted irrespective of their nationality. A considerable number of accidents have been received in the temporary premises we have just left; and some of them have been of a very serious character, requiring amputation and other surgical operations. The number of beds provided is thirty.

"Contemplating the very great success of the institution, I look forward hopefully to its continued usefulness. To insure its being a permanent benefit to the sick British poor of Paris, I am now taking measures for its endowment, and for its efficient management in the future. I wish to avail myself of this occasion to offer my sincere and heartfelt thanks to the two physicians, my good friends Sir John Rose Cormack and Dr Herbert, for their devoted services to the sick, and for the kind and efficient manner in which they have seconded all my wishes. I must also give my best thanks to Miss Smith, the ladysuperintendent, for her unwearied and successful performance of duties which are sometimes very difficult and onerous, and to all the nurses for their hearty co-operation. Here let me add that the duties of hospital physicians and nurses are very trying, and not unfrequently dangerous. A few weeks before we left our old quarters in the Route de la Révolte, we had the grievous misfortune to be visited by an outbreak of small-pox, by which four lives were lost-one being an excellent and devoted nurse. She died bravely, like a true soldier, doing her duty in the battle-field. In testimony of their regard, the staff of her fellow-workers have placed a memorial-stone over her grave."

The architectural beauty of the new Hertford British Hospital and its suitability in every detail for its destined purposes were the theme of universal admiration. The medical, surgical, and hygienic arrangements have been carried out regardless of expense. There is a complete service of baths and douches for out-patients as well as for resident patients, and a large garden is provided for each sex. There are four fracture-beds, made by McIlroy of New York; and the operationtable has also been furnished by that ingenious surgical mechanician. There is a well-appointed room for necropsies. (British Medical fournal, 1879.) 